\title{
SUPLEMENTAÇÃO DE PREBIÓTICO (MANANOLIGOSSACARÍDEO) NA DIETA DE DOIS GENÓTIPOS DE CODORNAS EM CRESCIMENTO
}

\author{
José Jordão Filho ${ }^{1}$ \\ José Humberto Vilar da Silva ${ }^{1,2}$ \\ Renato Andrade dos Santos \\ Veruska Dilyanne da Silva Gomes ${ }^{1}$ \\ Thiago de Sousa Melo ${ }^{4}$ \\ José Mares Felix Brito 5 \\ Janiele Ferreira da Silva ${ }^{6}$
}

JORDÃO FILHO, J.; SILVA, J. H. V. da; SANTOS, R. A. dos; GOMES, V. D. da S.; MELO, T. de S.; BRITO, J. M. F.; SILVA, J. F. da. Suplementação de prebiótico (mananoligossacarídeo) na dieta de dois genótipos de codornas em crescimento. Arq. Ciênc. Vet. Zool. UNIPAR, Umuarama, v. 20, n. 3, p. 135-141, jul./set. 2017.

RESUMO: O uso de antibióticos como aditivo melhorador de desempenho tem sido proibido pela possibilidade de favorecer o desenvolvimento de resistência bacteriana em humanos. Com isso, o objetivo da realização do trabalho foi avaliar o efeito da suplementação do prebiótico mananoligossacarídeo na alimentação de codornas japonesas e europeias em crescimento. Foram usadas 240 codornas de cada linhagem (Coturnix japonica e Coturnix coturnix) distribuídas em delineamento experimental inteiramente casualizado e arranjados em fatorial 2 x 4 (genótipos x níveis de suplementação de prebiótico) e seis repetições de dez aves. As codornas foram alimentadas com ração basal suplementadas com 0,0;0,05;0,10 e 0,15\% de mananoligossacarídeo em substituição ao inerte. Não houve efeito de interação para nenhuma das variáveis avaliadas ( $\mathrm{P}>0,05)$. Os níveis de suplementação do prebiótico não afetaram o desempenho e as características de carcaça $(\mathrm{P}>0,05)$ das codornas. $\mathrm{O}$ consumo de ração não foi alterado entre os genótipos $(\mathrm{P}>0,05)$, por outro lado, as codornas europeias apresentaram maior ganho de peso e melhor valor de conversão alimentar $(\mathrm{P} \leq 0,05)$ que as codornas japonesas. Os genótipos comerciais de codornas diferiram nas características de carcaça $(\mathrm{P} \leq 0,05)$. Recomenda-se formular rações sem suplementação do prebiótico mananoligossacarídeo para codornas japonesas e europeias de 21 a 42 dias de idade em ambiente considerando limpo.

PALAVRAS-CHAVE: Aditivos alimentares. Coturnicultura. Linhagem. Promotor de crescimento.

\section{PREBIOTIC SUPPLEMENTATION (MANNAN OLIGOSACCHARIDES) ON THE DIET OF TWO QUAILS GENOTYPES DURING GROWTH}

\begin{abstract}
The use of antibiotics as a feed additive promoting performance has been prohibited due to the possibility of favoring bacterial resistance in humans. Thus, the purpose of this paper was to assess the effect of mannan oligosaccharides supplementation in prebiotic feed provided to Japanese and European quails during the growth stage. A total of 240 quails for each strain (Coturnix japonica and Coturnix coturnix) were used, distributed in a completely randomized design and arranged in a $2 \times 4$ (genotypes x prebiotic supplementation levels) matrix, with six replications containing ten birds each. The quails were fed with basal feed supplemented with $0.0 ; 0.05 ; 0.10$ and $0.15 \%$ mannan oligosaccharide prebiotic. There was no interaction effect for any of the assessed variables $(\mathrm{P}>0.05)$. The prebiotic supplementation levels did not affect performance and carcass characteristics $(\mathrm{P}>0.05)$ of the quails. Feed intake was not changed between genotypes $(\mathrm{P}>0.05)$; on the other hand, European quails showed greater weight gain and better feed conversion rate $(\mathrm{P} \leq 0.05)$ than Japanese quails. Commercial genotypes differed inn carcass characteristics $(\mathrm{P} \leq 0.05)$. It is recommended that feeds are formulated without supplementation of mannan oligosaccharides prebiotic for Japanese and European quails aged 21 to 42 -days' old in production environment that are considered clean.
\end{abstract}

KEYWORDS: Food additives. Coturniculture. Growth promoter. Lineage.

\section{SUPLEMENTACIÓN PREBIÓTICA (MANANOLIGOSACÁRIDOS) EN DIETA DE DOS GENOTIPOS DE CODORNIZ EN CRECIMIENTO}

RESUMEN: El uso de antibióticos como aditivo de mejora de rendimiento ha sido prohibido por la posibilidad de promover el desarrollo de resistencia bacteriana en humanos. Por lo tanto, el propósito de llevar a cabo este estudio fue evaluar el efecto de la suplementación del prebiótico mananoligosacáridos en la alimentación de codornices japonesas y europeas en crecimiento. Se usaron 240 codornices de cada linaje (Coturnix japonica y Coturnix coturnix) distribuidas en un diseño completamente aleatorizado y dispuestos en factorial 2 x 4 (genotipos x niveles de suplementación prebiótica) y seis repe-

\footnotetext{
DOI: 10.25110 /arqvet.v20i3.2017.6196

'Departamento de Ciência Animal, CCHSA/UFPB, Bananeiras - PB.jjordaofilho@yahoo.com.br; veruska_sgomes@yahoo.com.br ${ }^{2} \mathrm{PDIZ} / \mathrm{CCA} / \mathrm{UFPB}$, Areia - PB e Pesquisador do CNPq-1B.

${ }^{3}$ Mestrado em Produção Animal, UFRN.

${ }^{4}$ Pós-doutorado, CCHSA/UFPB.

${ }^{5}$ Mestrado em Tecnologia Agroalimentar, CCHSA/UFPB.

${ }^{6}$ Licenciatura em Ciências Agrárias, CCHSA/UFPB.
} 
ticiones de diez aves. Las codornices fueron alimentadas con la dieta basal suplementadas con 0,$0 ; 0,05 ; 0,10$ y $0,15 \%$ mananoligosacárido en sustitución al inerte. No hubo efecto de interacción para ninguna de las variables evaluadas $(\mathrm{P}>0,05)$. Los niveles de suplementación del prebiótico no afectaron el rendimiento y las características del caparazón $(\mathrm{P}>0,05)$ de las codornices. El consumo de alimento no se cambió entre los genotipos ( $\mathrm{P}>0,05)$, por otro lado, las codornices Europeas presentaron mayor ganancia de peso y mejor valor de conversión del alimento $(\mathrm{p} \leq 0.05)$ que las codornices japonesas. Los genotipos comerciales de codornices difirieron en las características del caparazón $(p \leq 0.05)$. Se recomienda formular dietas sin suplementación del prebiótico mananoligosacáridos para codornices japonesas y europeas de 21 a 42 días de edad en ambiente considerado limpio.

PALABRAS CLAVE: Aditivos alimentarios. Cotornicultura. Linaje. Promotor del crecimiento.

\section{Introdução}

Os antibióticos foram largamente utilizados em dietas de aves comerciais com intuito de controlar agentes microbianos nocivos ao processo digestivo e, assim, favorecer o aproveitamento dos nutrientes da dieta. Contudo, questionamentos foram feitos sobre o uso de antibióticos em rações para promover o desempenho de aves, em virtude da possível presença de resíduos em carne e ovos que possam alterar o balanço microbiano intestinal, contribuindo para o surgimento de resistência em patógenos humanos (SILVA et al., 2003). O aparecimento de microrganismos resistentes a um antibiótico aumenta conforme a intensidade de seu uso (ALBINO et al., 2006). Em estudo com frangos de corte, foi observado resistência do microrganismo Enterococcus faecium aos antibióticos, avilamicina e virginiamicina (YOSHIMURA et al., 2000).

O uso profilático dos antibióticos como melhoradores de desempenho nas rações de animais foi iniciado na década de 1950, nos países da União Europeia, contudo, a data limite da proibição dos antibióticos com essa finalidade, devido à possibilidade de transferência de genes de resistência microbiana dos animais para os humanos, foi alcançada em janeiro de 2006 (CASTANON, 2007). A crescente demanda por alimentos de origem animal com selo orgânico tem realçado a importância de estudos envolvendo alternativas de melhoradores de desempenho em rações animais que garanta as características orgânicas dos produtos (SILVA et al., 2006).

Na procura de fontes substitutas que garanta a segurança dos alimentos, os nutricionistas veem nos prebióticos uma alternativa em potencial, pois, trata-se de substâncias presentes nos ingredientes de rações que não são digeridos no trato gastrointestinal da ave por falta de enzima endógena específica, permitindo a fermentação e o fornecimento de substrato para uma determina colônia de bactérias benéficas que desenvolvendo, garantirá o equilíbrio no epitélio intestinal (GIBSON; ROBERFROID, 1995). Neste contexto, os prebióticos beneficiam o hospedeiro por se tratar de um substrato nutricional para cepas de bactérias benéficas, resultando em melhor equilíbrio da microbiota intestinal e, favorecendo os processos de digestão e absorção dos nutrientes (SILVA; NORNBERG, 2003). Além de proteger a mucosa intestinal, de melhorar a digestibilidade de nutrientes e o teor de energia das rações (Silva et al., 2008), o uso de prebiótico como alternativa aos antibióticos pode melhorar a imagem dos produtos avícolas perante o mercado consumidor (ALBINO et al., 2006).

Flemming et al. (2004), observaram que o prebiótico (mananoligossacarídeo) poderia substituir o promotor de crescimento (olaquindox) sem perda no desempenho de frangos de corte até o abate por favorecer o desenvolvimento das vilosidades intestinais. Albino et al. (2006) demonstraram que prebióticos à base de mananoligossacarídeo podem substituir o antibiótico avilamicina em rações para frangos de corte, quanto à capacidade de melhorar o desempenho destes animais.

Avaliando trabalhos de uma década de estudos na comparação do uso de prebiótico mananoligossacarídeo em relação aos antibióticos como promotor de crescimento em aves, Hooge (2004) constatou melhora no ganho de peso e conversão alimentar para os animais alimentados com rações suplementadas com o prebiótico e melhora na viabilidade do plantel, atribuída a possível melhora no sistema imune das aves. Shashidhara e Devegowda (2003) observaram que mananoligossacarídeo melhorou a densidade espermática nos machos, a produção de ovos e a imunidade em galinhas reprodutoras pesadas quando comparadas aos animais alimentados com a dieta controle. Em codornas japonesas no período de postura, Oliveira et al. (2009) pesquisaram os efeitos da adição de mananoligossacarídeo em dietas com níveis reduzidos de cálcio e observaram que a suplementação de $0,10 \%$ do prebiótico proporcionou melhora no desempenho. No entanto, em codornas no período de crescimento, as informações ainda são escassas.

Com isso, o objetivo do presente trabalho foi avaliar o efeito da suplementação do prebiótico mananoligossacarídeo como promotores de absorção na alimentação de dois genótipos de codornas em crescimento.

\section{Material e métodos}

O experimento foi conduzido no Laboratório de Pesquisa em Nutrição de Aves do Centro de Ciências Humanas, Sociais e Agrárias da Universidade Federal da Paraíba, localizado no município de Bananeiras, Paraíba, Brasil.

O efeito da suplementação de prebiótico mananoligossacarídeo na dieta foi determinado em dois genótipos comerciais de codornas (japonesas e europeias) durante o período de 21 a 42 dias de idade.

As aves foram alojadas em boxes, medindo 1,0 x $1,5 \mathrm{~m}$, equipados com um bebedouro pendular, um comedouro tubular infantil, lâmpadas incandescentes de 60 watts e o piso era coberto com cama de maravalha.

As dietas foram formuladas à base de milho e farelo de soja (Tabela 1), respeitando às exigências nutricionais das codornas, conforme recomendações de Silva e Costa (2009). O prebiótico utilizado foi o mananoligossacarídeo (MOS), adicionado em substituição ao material inerte da ração.

Foram usadas 240 codornas de cada linhagem distribuídas em delineamento experimental inteiramente casualizado e arranjados em fatorial 2 x 4 (genótipos x níveis de 
suplementação de prebiótico) e seis repetições de dez aves.

elaborados do seguinte modo: 0,$0 ; 0,05 ; 0,10$ e $0,15 \%$ de suOs níveis de suplementação de mananoligossacarídeo foram plementação na ração.

Tabela 1: Composição alimentar e nutricional da ração experimental ${ }^{1}$

\begin{tabular}{|c|c|}
\hline Ingrediente & Dieta (kg) \\
\hline Milho & 57,430 \\
\hline Farelo de soja & 37,222 \\
\hline Calcário & 0,933 \\
\hline Fosfato bicálcico & 0,828 \\
\hline Óleo de soja & 2,590 \\
\hline DL-metionina & 0,217 \\
\hline Sal comum & 0,270 \\
\hline Premix vitamínico2 & 0,100 \\
\hline Premix mineral3 & 0,050 \\
\hline Cloreto de colina & 0,050 \\
\hline BHT4 & 0,010 \\
\hline Inerte (areia lavada) & 0,300 \\
\hline Total & 100,000 \\
\hline \multicolumn{2}{|l|}{ Composição química } \\
\hline Proteína bruta $(\%)$ & 22,000 \\
\hline Energia metabolizável corrigida (kcal/kg) & 3.050 \\
\hline Cálcio $(\%)$ & 0,770 \\
\hline Fósforo disponível (\%) & 0,270 \\
\hline Arginina total $(\%)$ & 1,470 \\
\hline Lisina total $(\%)$ & 1,178 \\
\hline Metionina total $(\%)$ & 0,554 \\
\hline Metionina + cistina total (\%) & 0,900 \\
\hline Treonina total $(\%)$ & 0,852 \\
\hline Triptofano total $(\%)$ & 0,276 \\
\hline Valina total $(\%)$ & 1,022 \\
\hline Sódio $(\%)$ & 0,150 \\
\hline Potássio (\%) & 0,857 \\
\hline Cloro $(\%)$ & 0,276 \\
\hline Balanço eletrolítico (mq/kg) & 206,652 \\
\hline
\end{tabular}

${ }^{1}$ Recomendações de Silva \& Costa (2009).

${ }^{2}$ Composição/kg do produto: vit. A - 10.000.000 UI; vit $\mathrm{D}_{3}-2.500 .0000 \mathrm{UI}$; vit. E - $15.000 \mathrm{mg}$; vit. $\mathrm{K}-2.000 \mathrm{mg}$; vit. $\mathrm{B}_{1}-2.000 \mathrm{mg}$; vit. $\mathrm{B}_{2}-4.000 \mathrm{mg}$; vit. $\mathrm{B}_{6}-4.000 \mathrm{mg}$; vit. $\mathrm{B}_{12}-15.000 \mathrm{mg}$; vit. $\mathrm{C}-50.000 \mathrm{mg}$; niacina $-30.000 \mathrm{mg}$; biotina $-60 \mathrm{mg}$; ácido fólico - $500 \mathrm{mg}$; ácido Pantotênico - $16.000 \mathrm{mg}$; B.H.T. $-125 \mathrm{mg}$.

${ }^{3}$ Composição/kg do produto: $\mathrm{Zn}-110.000 \mathrm{mg} ; \mathrm{Se}-360 \mathrm{mg}$; I - $1.400 \mathrm{mg} ; \mathrm{Cu}-20.000 \mathrm{mg} ; \mathrm{Mn}-156.000 \mathrm{mg} ; \mathrm{Fe}-96.000 \mathrm{mg}$.

${ }^{4} \mathrm{BHT}=$ Butil-Hidróxi-Tolueno (antioxidante).

Foram avaliadas as variáveis de desempenho: (consumo de ração, o ganho de peso e a conversão alimentar). $\mathrm{O}$ consumo de ração foi obtido pela diferença da ração fornecida e das sobras obtidas. O ganho de peso foi o resultado da diferença entre peso final e peso inicial das aves. A conversão alimentar foi obtida pela relação do consumo de ração com o ganho de peso.

Ao final do experimento, foram selecionadas duas aves por repetição, escolhidas com base no desvio-padrão de $\pm 5 \%$ da média de peso vivo das codornas aos 42 dias de idade na parcela. Em seguida, foram submetidas a jejum de sólidos de oito horas. As aves foram abatidas com um corte na jugular, depenadas e evisceradas manualmente. As codornas depenadas e evisceradas foram pesadas (sem pés e cabeça) e o rendimento de carcaça foi medido em relação ao peso vivo. Posteriormente, foram calculados os rendimentos de peito, pernas (coxa + sobrecoxa) e asa, em relação ao peso da carcaça eviscerada.

Os dados experimentais uma vez tabulados, foram submetidos à análise de variância fatorial, considerando o esquema 2 × 4 . Caso necessário, apenas os níveis de suplementação do prebiótico mananoligossacarídeo seriam submetidos ao modelo de regressão polinomial, considerando o valor do $\mathrm{R}^{2}$ e a resposta biológica das aves. As diferenças entre os genótipos de codornas foram analisados pelo teste "F", por meio do programa estatístico SAS 2012 (Statistical 
Analysis System).

\section{Resultados e discussão}

A suplementação do prebiótico "mananoligossacarídeo" na dieta de codornas de 21 a 42 dias de idade não afetou as características de desempenho $(\mathrm{P}>0,05)$ (Tabela 2$)$.
Não houve efeito de interação para nenhuma das variáveis avaliadas $(\mathrm{P}>0,05)$, portanto, os genótipos e os níveis de prebióticos comportaram-se de forma independente, por outro lado, o ganho de peso e a conversão alimentar apresentaram diferenças entre as linhagens de codornas $(\mathrm{P} \leq 0,05)$ (Tabela 2).

Tabela 2: Desempenho dos genótipos de codornas alimentadas com diferentes níveis de mananoligossacarídeo na ração

\begin{tabular}{|c|c|c|c|}
\hline Genótipo & Consumo de ração (g/ave/dia) & Ganho de peso (g/ave/dia) & Conversão alimentar $(\mathrm{kg} / \mathrm{kg})$ \\
\hline Codornas japonesas & $22,81 \pm 1,33$ & $3,77 \pm 0,25 b$ & $6,01 \pm 0,39 a$ \\
\hline Codornas europeias & $23,48 \pm 1,20$ & $4,89 \pm 0,44 \mathrm{a}$ & $4,83 \pm 0,42 b$ \\
\hline \multicolumn{4}{|c|}{ Mananoligossacarídeo-MOS (\%) } \\
\hline 0,00 & $22,74 \pm 1,12$ & $4,38 \pm 0,75$ & $5,28 \pm 0,71$ \\
\hline 0,05 & $23,72 \pm 1,41$ & $4,37 \pm 0,74$ & $5,55 \pm 0,89$ \\
\hline 0,10 & $23,35 \pm 1,62$ & $4,33 \pm 0,63$ & $5,39 \pm 0,59$ \\
\hline 0,15 & $22,76 \pm 0,74$ & $4,24 \pm 0,62$ & $5,46 \pm 0,72$ \\
\hline \multicolumn{4}{|l|}{ Anova } \\
\hline Genótipo & ns & $\mathrm{P} \leq 0,01$ & $\mathrm{P} \leq 0,01$ \\
\hline MOS & ns & ns & ns \\
\hline Genótipo*MOS & $\mathrm{ns}$ & ns & ns \\
\hline $\mathrm{CV}(\%)$ & 5,41 & 8,58 & 7,54 \\
\hline
\end{tabular}

$\mathrm{a}, \mathrm{b}=$ Médias seguidas de letras minúsculas diferentes na coluna diferem entre si pelo teste $\mathrm{F}(\mathrm{P} \leq 0,01)$.

ns $=$ não significativo.

$\mathrm{CV}=$ coeficiente de variação.

Os níveis de suplementação do prebiótico na ração não influenciaram o desempenho das codornas, justificado provavelmente, pela ausência de desafio microbiano. A eficácia de um promotor de crescimento depende da contaminação ambiental e da intensidade do desafio microbiano que o organismo da ave está exposto (ROURA et al., 1992). Como o ambiente experimental foi limpo e desinfetado, essa é provavelmente a hipótese que justifica a semelhança de resultados entre as dietas sem e com suplementação de "MOS". Albino et al. (2006) observaram que o prebiótico à base de mananoligossacarídeo pode substituir o antibiótico avilamicina em rações de frangos de corte alojados em cama reaproveitada, no entanto, Waldroup et al. (2003) não encontraram diferenças entre antimicrobiano: antibiótico e prebiótico no desempenho de frangos de corte alojados em cama nova.

Os efeitos do prebiótico a base de mananoligossacarídeo sobre o desempenho das aves parece ter maior eficiência de utilização quando estas são submetidas a ambiente com desafio microbiano. Trabalhando com aves que receberam dietas contendo mananoligossacarídeo e desafiadas com Salmonella Typhimurium, Spring et al. (2000), observaram redução positiva deste microrganismo no ceco das aves quando suplementadas com o prebiótico. Reforçando a hipótese, Silva et al. (2006) observaram melhora na conversão alimentar de frangas alojadas em cama nova em relação aquelas criadas em cama reciclada. Outro efeito da suplementação do prebiótico sobre o desempenho das aves pode ser verificado em desafio térmico. Silva et al. (2009) observaram que a inclusão de $0,15 \%$ de mananoligossacarídeo "MOS" na ração pré-inicial de frangos proporcionou maior ganho de peso na temperatura baixa $\left(27^{\circ} \mathrm{C}\right)$, o que pode estar relacionado à ação benéfica do prebiótico sobre a densidade dos vilos das aves criadas nessa temperatura, aumentando a superfície de absorção de nutrientes e melhorando o aproveitamento do alimento.

Apesar da inclusão de $0,10 \%$ de mananoligossacarídeos à dieta melhorar a digestibilidade ileal e a retenção de proteína, cálcio e fósforo e os valores de energia metabolizável em dietas para frangos de corte (OLIVEIRA et al., 2007), os níveis estudados não foram suficientes para proporcionar diferenças no desempenho das codornas. Os resultados de desempenho semelhantes entre os níveis de mananoligossacarídeos suplementados na ração das codornas foram observados por Stanczuk et al. (2005) quando não encontraram diferenças entre a dieta sem suplementação e com o nível de $0,10 \%$ de mananoligossacarídeo sobre o consumo de ração, o ganho de peso, e a conversão alimentar em perus.

Waldroup et al. (2003) relataram não haver diferenças no desempenho de frangos aos 42 dias de idade atribuídas ao uso de mananoligossacarídeos ou antibióticos nas dietas. Os prebióticos a base de fruto-oligossacarídeos $(0,9 \%)$, lactose $(0,5 \%)$, manose $(0,05 \%)$ e sacarose $(2,0 \%)$ não influenciaram o desempenho dos frangos de um a 21 e de 22 a 42 dias de idade em comparação com a ração basal com antibiótico (avilamicina) no trabalho conduzido por Dionízio et al. (2002).

Silva et al. (2008) também não observaram melhora de ganho de peso de frangos aos sete, 14 e 21 dias de idade das aves alimentadas com mananoligossacarídeos em relação aquelas que ingeriram ração com antibiótico, por outro lado, recomendaram a substituição do antibiótico pelo prebiótico, devido a conservação da microbiota e da integridade da mucosa intestinal, avaliado em microscopia eletrônica.

No presente trabalho, as codornas europeias apre- 
sentaram maior ganho de peso e melhor valor de conversão alimentar $(\mathrm{P} \leq 0,05)$ que as codornas japonesas. Os achados consolidam a hipótese de uso da codorna europeia no segmento de corte. Isso é de extrema importância, pois, segundo Oliveira et al. (2005), as codornas destinadas ao abate no Brasil, geralmente são eventuais machos que foram classificados erroneamente no processo de sexagem ou fêmeas em final de postura. Contudo, os autores avaliaram a análise sensorial da carne de codornas europeias (tipicamente para corte) e observaram que as carcaças apresentam atributos sensoriais suficientes (aroma, suculência e sabor) para o consumo humano.

A diferença entre os genótipos pode ser atribuída às divergências genéticas, onde codornas europeias apresentam maior taxa de deposição para proteína (JORDÃO FILHO et al., 2012) exigem mais energia para mantença e são mais eficientes no uso da energia (Jordão Filho et al., 2011) e proteína para ganho que codornas japonesas (JORDÃO FILHO et al., 2012). De acordo com Silva et al. (2004a), codornas japonesas aumentam o peso vivo em cerca de sete vezes de um a 14 dias de idade. No entanto, Silva et al. (2004b) em outro trabalho, não encontraram a mesma evolução do peso vivo das codornas na fase de crescimento ( 15 a 32 dias). Por outro lado, segundo Silva e Costa (2009), as codornas europeias ganham cerca de $200 \mathrm{~g}$ até os 21 dias de idade, constituindo aproximadamente 25 vezes o peso de um dia de vida. $\mathrm{O}$ rápido crescimento das aves europeias em relação às codornas japonesas ocorre, provavelmente, devido à maior deposição de proteína e gordura corporal. Isto explica as diferenças de ganho de peso e conversão alimentar apresentadas acima. Em estudo de curva de crescimento, Silva e Costa (2009) apresentaram dados que as codornas europeias tinham maior taxa de ganho diário e maior peso à maturidade que as japonesas. Portanto, as diferenças na nutrição de codornas japonesas e europeias são semelhantes àquelas existentes entre frangos e galinhas poedeiras, em que rações formuladas para uma espécie não devem ser usadas na alimentação da outra linhagem (SILVA \& COSTA, 2009).

Não houve interação entre genótipo e nível de prebiótico estudado sobre as características de carcaça $(\mathrm{P}>0,05)$. Além disso, não ocorreu diferenças $(\mathrm{P}>0,05)$ nos resultados de sua suplementação para nenhuma das características de carcaça avaliadas $(\mathrm{P}>0,05)$ (Tabela 3$)$, indicando que os níveis de suplementação do prebiótico "mananoligossacarídeo" estudado não afetam estas variáveis.

Tabela 3: Características de carcaça dos genótipos de codornas alimentadas com diferentes níveis de mananoligossacarideo na ração

\begin{tabular}{l|c|c|c|c|c}
\hline \multirow{2}{*}{ Genótipo } & \multirow{2}{*}{ Peso vivo (g) } & \multicolumn{5}{c}{ Rendimento (\%) } \\
\cline { 3 - 7 } & & Carcaça & Peito & Coxa e sobrecoxa & Asa \\
\hline Codornas japonesas & $175,25 \pm 6,59 \mathrm{~b}$ & $70,67 \pm 2,81 \mathrm{~b}$ & $33,00 \pm 1,83 \mathrm{~b}$ & $22,46 \pm 1,46 \mathrm{a}$ & $8,50 \pm 0,62 \mathrm{a}$ \\
\hline Codornas europeias & $225,38 \pm 8,85 \mathrm{a}$ & $79,02 \pm 4,03 \mathrm{a}$ & $34,66 \pm 2,41 \mathrm{a}$ & $20,47 \pm 1,03 \mathrm{~b}$ & $8,05 \pm 0,59 \mathrm{~b}$ \\
\hline \multicolumn{7}{|c|}{ Mananoligossacarídeo-MOS $(\%)$} \\
\hline 0,00 & $202,11 \pm 28,48$ & $74,00 \pm 5,45$ & $34,14 \pm 2,42$ & $21,94 \pm 1,33$ & $8,52 \pm 0,52$ \\
\hline 0,05 & $200,83 \pm 26,18$ & $75,09 \pm 5,53$ & $33,59 \pm 2,99$ & $20,83 \pm 1,53$ & $8,28 \pm 0,69$ \\
\hline 0,10 & $198,57 \pm 27,70$ & $76,71 \pm 5,60$ & $34,22 \pm 1,85$ & $21,43 \pm 1,91$ & $7,85 \pm 0,46$ \\
\hline 0,15 & $199,75 \pm 26,95$ & $73,56 \pm 5,34$ & $33,36 \pm 1,85$ & $21,65 \pm 1,59$ & $8,45 \pm 0,71$ \\
\hline
\end{tabular}

Anova

\begin{tabular}{l|c|c|c|c|c}
\hline Genótipo & $\mathrm{P} \leq 0,01$ & $\mathrm{P} \leq 0,01$ & $\mathrm{P} \leq 0,01$ & $\mathrm{P} \leq 0,01$ & $\mathrm{P} \leq 0,01$ \\
\hline MOS & $\mathrm{ns}$ & $\mathrm{ns}$ & $\mathrm{ns}$ & $\mathrm{ns}$ & $\mathrm{ns}$ \\
\hline Genótipo*MOS & $\mathrm{ns}$ & $\mathrm{ns}$ & $\mathrm{ns}$ & $\mathrm{ns}$ & $\mathrm{ns}$ \\
\hline CV $(\%)$ & 4,11 & 4,63 & 6,41 & 5,95 & 6,88 \\
\hline
\end{tabular}

a,b médias seguidas de letras distintas na coluna diferem entre si pelo teste $\mathrm{F}(\mathrm{P} \leq 0,05)$.

ns = não significativo. $\mathrm{CV}=$ coeficiente de variação.

Estes resultados foram evidenciados por Dionizio et al. (2002), onde observaram que prebióticos não provocaram alterações nas características de carcaça em frangos de corte, reforçando a hipótese do presente trabalho. Albino et al. (2006), não encontraram diferenças para rendimento de carcaça, porém, observaram maior rendimento de peito de frangos alimentados com dietas suplementadas com mananoligossacarídeo em relação àqueles alimentados com ração sem o prebiótico. A hipótese mais provável que ajuda a justificar os resultados, é também a ausência de desafio microbiano para as codornas durante o período experimental.

Os efeitos sobre o desempenho e característica de carcaça com a utilização de mananoligossacarídeo em dietas para aves são variáveis e podem ser influenciados por diversos fatores, como o nível de suplementação do prebiótico na ração (WALDROUP et al., 2003).
A melhora do desempenho das aves alimentadas com dietas suplementadas com antimicrobiano é explicada pela capacidade que esse tem de induzir a seleção de microbiota intestinal a favor da bactéria benéfica, contudo, os resultados são dependentes do nível de estresse dos animais (MATHEW et al., 1993).

Se as aves estão em condições não estressantes, supõe-se que a microbiota esteja em condição de equilíbrio, ou seja, com ou sem o fornecimento de prebióticos as respostas obtidas serão muito semelhantes. No entanto, quando em condição de estresse (ventilação deficiente, densidade inadequada, variações ambientais bruscas, troca de dieta, presença de patógenos), o efeito benéfico do fornecimento de prebióticos sobre a resposta biológica é evidenciado (MATHEW et al., 1993).

O efeito da suplementação do prebiótico sobre o 
desempenho das aves pode ser constatado pela ausência de desafio microbiano. A interação do ambiente de criação e o uso de antibióticos como promotores de absorção sobre o desempenho de aves vem sendo estabelecida em trabalhos clássicos. Coates et al., (1963), avaliaram o ganho de peso de frangos em ambiente livre de patógenos e não observaram diferenças pela presença ou ausência de antibiótico na ração. Mais tarde, Roura et al. (1992) confirmaram a informação de que, em ambientes sujos, o uso de antibióticos promove melhor desempenho. Finalmente, pintinhas de postura criadas em cama nova e alimentadas sem adição de antimicrobiano na ração apresentaram desempenho semelhante àquelas criadas em cama reutilizada, alimentadas com ração contendo antibiótico (SILVA et al., 2006). Isso reforça a hipótese de que um bom programa de limpeza e desinfecção poder ser a melhor iniciativa para garantir bons índices de desempenho sem desrespeitar a legislação que proibe o uso de antibiótico na dieta. Portanto, as perspectivas de substituição dos antibióticos como promotores de crescimento que tem sido direcionado para o uso de probióticos, ácidos orgânicos, extratos vegetais, óleos essenciais, subprodutos de origem animal e prebióticos, poderiam ser atendidos pelo uso eficiente de programa de limpeza e desinfecção.

Os prebióticos são compostos biologicamente seguros à saúde humana e animal, contudo, as respostas biológicas na nutrição animal nem sempre são evidenciadas, com a dosagem adicionada, com adaptação e a seletividade da microbiota ao prebiótico ou ao nível de estresse animal (SILVA; NORNBERY, 2003). Neste sentido, qualquer um dos níveis de suplementação do prebiótico poderia ser utilizado, desde que, as condições financeiras da alimentação sejam satisfatórias, principalmente, se as aves estiverem alojadas em condição de estresse.

\section{Conclusão}

Recomenda-se a formulação de rações para codornas japonesas e europeias de 21 a 42 dias de idade sem a suplementação de prebiótico mananoligossacarideo em ambiente considerado limpo.

\section{Referências}

ALBINO, L. F. T. et al. Uso de prebiótico à base de mananoligossacarideo em rações para frangos de corte.

Revista Brasileira de Zootecnia, v. 35, n. 3, p. 742-749, 2006.

CASTANON, J. I. R. History of the use of antibiotic as growth promoters in European Poultry Feeds. Poultry Science, v. 86, p. 2466-2471, 2007.

COATES, M. E. et al. A comparison of the growth of chicks in the Gustafsson germ-free apparatus and in a conventional environment, with and without dietary supplements of penicillin. British Journal Nutrition, v. 17, p. 141-151, 1963.

DIONIZIO, M. A. et al. Prebióticos como promotores de crescimento para frangos de corte - desempenho e rendimento de carcaça. Ciência e Agrotecnologia, Edição
Especial, p. 1580-1587, 2002.

FLEMMING, J. S.; FREITAS, J. R. S.; FONTOURA, P. Use of mannanoligosaccharides in broiler feeding. Brazilian Journal of Poultry Sciencem, v. 6, n. 3, p. 159161,2004

GIBSON, G. R.; ROBERFROID, M. B. Dietary modulation of the human colonic microbiota: introducing the concept of prebiotics. Journal of Nutrition, v. 125, n. 6, p. 1401-1412, 1995.

HOOGE, D. M. Meta-analysis of broiler chicken pen trials evaluating dietary mannan oligosaccharide, 1993-2003.

International Journal of Science, v. 3, n. 3, p. 163-74, 2004.

JORDÃO FILHO, J. et al. Energy requirement for maintenance and gain for two genotypes of quails housed in different breeding rearing systems. Revista Brasileira de Zootecnia, v. 40, n. 11, p. 2415-2422, 2011.

JORDÃO FILHO, J. et al. Requirement for maintenance and gain of crude protein for two genotypes of growing quails. Revista Brasileira de Zootecnia, v. 41, n. 9, p. 2048-2054, 2012.

MATHEW, A. G. et al. Effect of galactan on selected microbial populations and $\mathrm{pH}$ and volatile fatty acids in the ileum of the weanling pig. Journal Animal Science, v. 71, n. 6 , p. 1503-1509, 1993.

OLIVEIRA, E. G. et al. Avaliação sensorial de carne de codornas para corte, abatidas ao 35, 56 e 77 dias de idade. Veterinária e Zootecnia, v. 12, n. 1/2, p. 61-68, 2005.

OLIVEIRA, M. C. et al. Utilização de nutrientes de dietas contendo mananoligossacarídeo e/ou complexo enzimático para frangos de corte. Revista Brasileira de Zootecnia, v. 34, n. 4, p. 825-831, 2007.

OLIVEIRA, M. C. et al. Dieta com mananoligossacarídeo e níveis reduzidos de cálcio para codornas japonesas. Revista Brasileira de Zootecnia, v. 38, n. 11, p. 2193-2197, 2009.

ROURA, E.; HOMENDES, J.; KLASSING, K. Prevention of immunologic stress contributes to the growth-permitting ability of dietary antibiotic in chicks. Journal of Nutrition, v. 122 , n. 12 , p. 2383-2390, 1992.

SHASHIDHARA, R. G.; DEVEGOWDA, G. Effect of dietary mannan oligosaccharide on broiler breeder production traits and immunity. Poultry Science, v. 82, n. 8, p. 1319-1325, 2003.

SILVA, J. H. V.; COSTA, F. G. P. Tabelas para codornas japonesas e europeias: tópicos especiais, composição de alimento e exigências nutricionais. 2. ed. Jaboticabal: FUNEP, 2009. 107 p.

SILVA, J. H. V. et al. Efeito da substituição dos 
antimicrobianos pelo ovo desidratado na fase pré-inicial de frangas de dois grupos genéticos alojadas em camas nova e reciclada. Revista Brasileira de Zootecnia, v. 35, n. 5, p. 2077-2084, 2006.

SILVA, C. J. et al. Uso de prebiótico (Bio-Mos ${ }^{\circledR}$ ) associado a diferentes níveis protéicos em rações de frango de corte. Agrarian, v. 1, n. 1, p. 105-116, 2008.

SILVA, J. H. V.; JORDÃO FILHO, J.; SILVA, E. L. Efeito do alho (Allium sativum linn.), probiótico e virginiamicina antes, durante e após o estresse induzido pela muda forçada em poedeiras semipesadas. Revista Brasileira de Zootecnia, v. 32, n. 6, p. 1697-1704, 2003.

SILVA, J. H. V. et al. Exigências de mantença e de ganho de proteína e de energia em codornas japonesas (Coturnix coturnix japonica) na fase de 1 a 12 dias de idade. Revista Brasileira de Zootecnia, v. 33, n. 5, p. 1209-1219, 2004a.

SILVA, J. H. V. et al. Exigências de mantença e de ganho em proteína e energia em codornas japonesas (Coturnix coturnix japonica) na fase de 15 a 32 dias. Revista Brasileira de Zootecnia, v. 33, n. 5, p. 1220-1230, 2004b.

SILVA, L. P.; NORNBERG, J. L. Prebióticos na nutrição de não ruminantes. Ciências Rural, v. 33, n. 5, p. 983-990, 2003.

SILVA, V. K. et al. Desempenho de frangos de corte de 1 a 21 dias de idade alimentados com rações contendo extrato de leveduras e prebiótico e criados em diferentes temperaturas. Revista Brasileira de Zootecnia, v. 38, n. 4, p. 690-696, 2009.

SPRING, P. et al. The effects of dietary Mannanoligosaccharides on cecal parameter and the concentrations of enteric bacteria in the ceca of Salmonellachallenged broiler chicks. Poultry Science, v. 79, n. 2, p. 205-211, 2000.

STANCZUK, J. et al. Indices of response of young turkeys to diets containing mannanoligosaccharide or inulin.

Veterinarija Ir Zootechnika, v. 31, n. 53, p. 98-101, 2005.

WALDROUP, P. W.; FRITTS, C. A.; FENGLAN, Y. Utilization of Bio-Mos ${ }^{\circledR}$ Mannan Oligosaccharide and Bioplex $^{\circledR}$ copper in broiler diets. International Journal of Poultry Science, v. 2, n. 1, p. 44-52, 2003.

YOSHIMURA, H. et al. Antimicrobial susceptibilities of enterococci isolated from faeces of broiler and layer chickens. Journal of Applied Microbiology, v. 31, n. 6, p. 427-432, 2000.. 